\title{
Study of Serum Creatine Kinase Level, Cystatin C and Creatinine Level in Hypothyroidism
}

\author{
Tejomani $\mathrm{M}^{1}$, Meera $\mathrm{KS}^{2^{*}}$, Krishnamurthy $\mathrm{U}^{3}$ \\ ${ }^{1}$ Department of Biochemistry, ESI Post Graduate Institute of Medical Science and Research, Bengaluru-560010, Karnataka, India \\ ${ }^{2,3}$ Department of Biochemistry, M.S. Ramaiah Medical College, MSR Nagar, Bengaluru - 560054, Karnataka, India
}

DOI: $\underline{10.36348 / \text { sijb.2019.v02i12.004 }}$ | Received: 18.12 .2019 | Accepted: 25.12 .2019 | Published: 28.12 .2019

*Corresponding author: Dr. K. S. Meera

\section{Abstract}

Hypothyroidism is a common endocrine disorder associated with increase in peripheral vascular resistance and decreased cardiac output. The increase in peripheral resistance can predispose to alteration in renal hemodynamics including reduced renal blood flow associated with diminution of glomerular filtration. The study was taken up to determine the influence of thyroid hormones on serum cystatin $\mathrm{C}$, creatine kinase and creatinine level in hypothyroids and to determine the extent of renal involvement in these cases. Serum $\mathrm{T}_{3}, \mathrm{~T}_{4}, \mathrm{TSH}$, Total creatine kinase, Cystatin $\mathrm{C}$ and creatinine levels were estimated. Creatinine clearance was calculated using Cockcroft Gault formula and eGFR by using MDRD formula. The elevation of serum creatinine levels in hypothyroids in the study may be due to increase in total creatine kinase level either due to myopathy or due to decreased clearance by kidney. In the study there is paradoxical relation of elevation of serum creatinine and decrease in serum cystatin $\mathrm{C}$ in hypothyroidism.

Keywords: Creatinine, creatinine clearance, cystatin C, eGFR, hypothyroidism, renal plasma flow, thyroid hormone, total creatine kinase.

Copyright @ 2019: This is an open-access article distributed under the terms of the Creative Commons Attribution license which permits unrestricted use, distribution, and reproduction in any medium for non-commercial use (NonCommercial, or CC-BY-NC) provided the original author and source are credited.

\section{INTRODUCTION}

Thyroid hormone affects nearly every organ system in the body. It is produced and secreted by the thyroid gland under the control of the anterior pituitary hormone: thyroid stimulating hormone (TSH), which in turn is regulated by hypothalamic thyrotropin-releasing hormone. Thyroxine (T4) is produced only by the thyroid gland, whereas triiodothyronine (T3), the more biologically active form of thyroid hormone, is produced primarily through local deiodination of T4 by the enzyme 5'- deiodinase in other tissues, including kidney [1]. The kidney contains the D1 isoform of this enzyme, which becomes less active in uremia. Thyroid hormone exerts its effect primarily by binding to thyroid hormone nuclear receptors, which can affect gene transcription by binding to thyroid hormone response elements of target genes [2]. Thyroid hormones can also exert nongenomic effects by binding to elements on the plasma membrane and cytoplasm.

Thyroid hormone directly influences the expression and/or activity of a number of ion channels and transporters. The impact of thyroid dysfunction on renal function is highlighted by studies substantiating clinical hypothyroidism is common in patients with estimated GFR, $60 \mathrm{ml} / \mathrm{min}$ per $1.73 \mathrm{~m}^{2}$ [3]. Renal function deterioration secondary to hypothyroidism involves diverse mechanisms including hemodynamic defects including negative inotropic effect on the heart, reduced circulating intravascular volume and increased peripheral resistance with renal vasoconstriction [4]. Myopathy may be the exclusive clinical manifestation of hypothyroidism in some cases along with rise in serum creatine kinase level, lactate dehydrogenase and aldolase levels. Skeletal muscle could be the major source of increase in plasma CK in hypothyroidism. Total CK level is considered to be a sensitive and excellent biochemical marker for diagnosis of neuromuscular diseases. Hypothyroidism is a common cause of endocrine myopathy and should be considered in patients with unexplained persistent elevation of serum muscle enzymes, which are higher in patients with hypothyroidism.

Thyroid hormones are necessary for growth and development of the kidney in addition to maintenance of water and electrolyte homeostasis. Kidney is involved in metabolism and elimination of thyroid hormone. The decline in kidney function is accompanied by changes in the process of synthesis, secretion, metabolism and elimination of thyroid 
hormone. Thyroid hormone affects tubular transport of sodium and potassium via their actions on the sodiumpotassium ATP pump $\left(\mathrm{Na}^{+} / \mathrm{K}^{+}\right.$ATPase $)$and permeability of potassium in the membrane of proximal tubules [5]. Thyroid dysfunction can bring about significant change in renal function by affecting renal blood flow, GFR, tubular function, electrolytes homeostasis, electrolyte pump functions and kidney structure. The most common kidney derangement associated to hypothyroidism includes elevation of serum creatinine level [6].

Cystatin $\mathrm{C}$ is a cysteine proteinase inhibitor and is produced at a constant rate by most nucleated cells, freely filtered at the glomerulus. Cystatin $\mathrm{C}$ is reabsorbed and metabolized by proximal tubular epithelial cells. Serum cystatin C (Cys C) is a novel marker for kidney function that has been claimed to be superior to serum creatinine [7]. The aim of the study was to determine the influence of thyroid hormone on the creatine kinase level and to estimate serum creatinine and cystatin $\mathrm{C}$ level in hypothyroidism to measure extent of renal involvement. The study would further help to interpret the alteration in serum creatinine and cystatin $\mathrm{C}$ level in hypothyroidism.

\section{MATERIALS AND METHODS}

The study population consisted of about 40 clinically suspected and biochemically confirmed hypothyroid patients who visited the out-patient clinic of Department of Medicine and Endocrinology, M S Ramaiah Teaching Hospital, Bangalore. The control group included 40 healthy euthyroid subjects who attended the hospital for routine health check-up. A detailed history including drug history was taken from the patient.

\section{Inclusion Criteria}

Clinically diagnosed and biochemically confirmed hypothyroid cases in the age group of 25 to 55 years of either gender. Patients were considered as hypothyroid based on $\mathrm{T}_{3}, \mathrm{~T}_{4}$ and $\mathrm{TSH}$ values (Normal reference range: - $\mathrm{T}_{3}: 1.08-4.14 \mathrm{nmol} / \mathrm{L}, \mathrm{T}_{4}$ : Males: 59 135 nmol/L, Females: 65-138 nmol/L, TSH: 0.5-4.3 $\mu \mathrm{IU} / \mathrm{ml})$. Raised serum TSH levels with normal or low $\mathrm{T}_{3}$ and $\mathrm{T}_{4}$ levels were categorized as hypothyroid cases.

\section{Exclusion Criteria}

Patients with impaired renal function (Serum creatinine $>1.2 \mathrm{mg} / \mathrm{dl}$ in females and $>1.4 \mathrm{mg} / \mathrm{dl}$ in males), with ischemic heart disease and cerebrovascular disease, with hypertension and diabetes mellitus, with rheumatoid arthritis, Duchenne's muscular dystrophy, polymyositis and other causes for transient increase in CK were excluded from the study.

An informed consent was taken before the collection of the sample from cases and controls. The control subjects had the same exclusion criteria as the cases and were not on any drug regimens which could influence the study. The ethical clearance was obtained for the study. About $5 \mathrm{ml}$ of blood sample was collected in a yellow vacutainer, devoid of any anticoagulant and contained clotting agent to hasten the process of clotting. Blood samples after overnight fasting were collected from cases and controls. The samples were centrifuged and the serum was separated at the earliest. The serum sample was used for the estimation of $\mathrm{T}_{3}, \mathrm{~T}_{4}$, $\mathrm{TSH}$, cystatin $\mathrm{C}$, creatinine and total creatine kinase level.

Serum $\mathrm{T}_{3}, \mathrm{~T}_{4}, \mathrm{TSH}$ was estimated on the autoanalyser Roche/Hitachi COBAS e601 (Elecsys) by the electrochemiluminescence (ECLIA). Serum total creatine kinase level was estimated by IFCC NAC Activated method. Serum creatinine was estimated by modified Jaffe's reaction and immunoturbidimetric method for assay of Cystatin C. Creatinine clearance was calculated by using Cockcroft Gault Formula. Creatinine clearance $\left(\mathrm{ml} / \mathrm{min} / 1.73 \mathrm{~m}^{2}\right)=(140$ - Age $X$ mass in $\mathrm{kg} \mathrm{X}$ [0.85 if female]) / [72 X serum creatinine $(\mathrm{mg} / \mathrm{dl})]$ [7]. eGFR (estimated Glomerular Filtration Rate) was calculated, using MDRD (Modification of diet in renal disease) formula. eGFR $\left(\mathrm{ml} / \mathrm{min} / 1.73 \mathrm{~m}^{2}\right)$ $=186 \times(\text { Plasma } / \text { serum creatinine } \mathrm{mg} / \mathrm{dl})^{-1.154} \mathrm{x}(\text { age })^{-}$ ${ }^{0.203} \mathrm{x}$ (1.210 if black) $\mathrm{x}(0.742$ if female) [8]. eGFR greater than $90 \mathrm{ml} / \mathrm{min} / 1.73 \mathrm{~m}^{2}$ were considered to be normal.

The results are expressed in Mean \pm SD. Significance was assessed at $5 \%$ level of significance. Student $\mathrm{t}$ test (two tailed, independent) has been used to find the significance of study parameters. Pearson correlation coefficient was used to study relation between the various study parameters.

\section{RESULTS AND DISCUSSION}

The data of the euthyroid controls and hypothyroid cases was compared with respect to serum $\mathrm{T}_{3}, \mathrm{~T}_{4}$ (levels of thyroid hormone), TSH (thyroid stimulating hormone), Total $\mathrm{CK}$ activity, cystatin $\mathrm{C}$, creatinine and creatinine clearance and glomerular filtration rate as eGFR. The distribution of age in cases and controls are shown in Table 1. Hypothyroidism was found more common between 25-35 years age group. The prevalence of hypothyroidism was higher among females as is observed worldwide over (Table 1). Hypothyroids in the study have more weight as compared to controls (Fig 1). TSH was found nearly ten times higher in cases when compared to controls (Fig 2). Thyroid profile levels in hypothyroids and euthyroids are shown in Figure 2. There is significant decrease in T3, T4, and increase in TSH levels as shown in Table 2. The total CK levels were highly significant in hypothyroids in comparison to controls (Fig 3). A significant rise in serum creatinine levels was seen in hypothyroid cases as compared to controls $(\mathrm{p}<0.001) \quad($ Fig 4$)$. The creatinine clearance was decreased in cases when compared with controls (Fig 5). eGFR was decreased in cases as compared to 
controls (Table 2). There was decrease in cystatin $\mathrm{C}$ levels in hypothyroid cases as compared to euthyroid controls (Fig 6).

Table-1: Comparison of demographic profiles in hypothyroid case and euthyroid controls

\begin{tabular}{|c|c|c|}
\hline $\begin{array}{c}\text { Demographic } \\
\text { profiles }\end{array}$ & $\begin{array}{c}\text { Hypothyroid } \\
\text { Cases }(\mathbf{n}=\mathbf{4 0})\end{array}$ & $\begin{array}{c}\text { Euthyroid } \\
\text { Controls }(\mathbf{n}=\mathbf{4 0})\end{array}$ \\
\hline Age in years & $33.96 \pm 10.17$ & $41.85 \pm 11.91$ \\
\hline Gender & & $2(15.4 \%)$ \\
\hline Males & $6(42.9 \%)$ & $11(84.6 \%)$ \\
\hline Females & $8(57.1 \%)$ & $56.92 \pm 7.3(\mathrm{p}$ value \\
$0.027 *)$
\end{tabular}

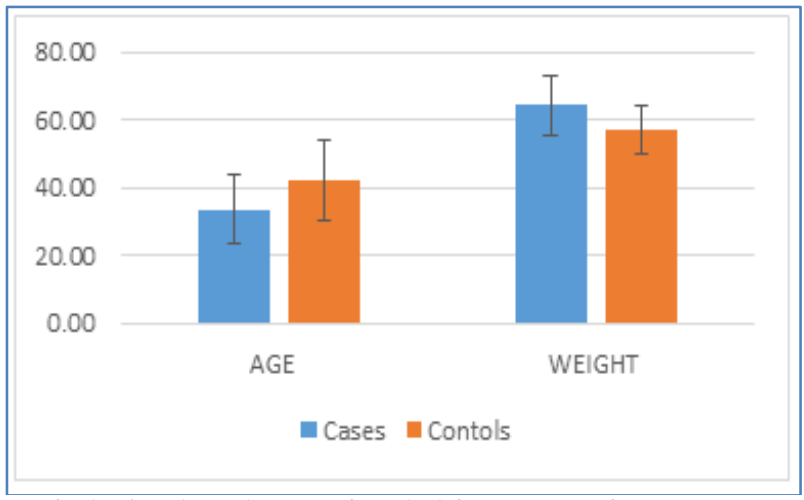

Fig-1: Age (years) and weight (kg) in hypothyroid cases and euthyroid controls.

Table-2: Comparison of biochemical profiles in hypothyroid cases and euthyroid controls

\begin{tabular}{|l|l|l|l|}
\hline Biochemical Profiles & $\begin{array}{l}\text { Hypothyroid } \\
\text { Cases }(\mathbf{n = 4 0})\end{array}$ & $\begin{array}{l}\text { Euthyroid } \\
\text { Controls }(\mathbf{n = 4 0})\end{array}$ & P value \\
\hline $\mathrm{S} . \mathrm{T} 3 \mathrm{nmol} / \mathrm{L}$ & $0.60 \pm 0.34$ & $1.88 \pm 0.38$ & $<0.001^{* *}$ \\
\hline $\mathrm{S}$. T4 $\mathrm{nmol} / \mathrm{L}$ & $20.51 \pm 19.28$ & $111.29 \pm 22.4$ & $<0.001^{* *}$ \\
\hline S. TSH uIU/ml & $214.85 \pm 43.16$ & $2.67 \pm 1.19$ & $<0.001^{* *}$ \\
\hline S. Total CK IU/L & $544.70 \pm 90.86$ & $59.75 \pm 34.33$ & $<0.001^{* *}$ \\
\hline S. Creatinine $\mathrm{mg} / \mathrm{dl}$ & $1.14 \pm 0.22$ & $0.81 \pm 0.18$ & $<0.001^{* *}$ \\
\hline Creatinine Clearance $\mathrm{ml} / \mathrm{min}$ & $79.90 \pm 16.5$ & $91.19 \pm 40.99$ & 0.350 \\
\hline eGFR $\mathrm{ml} / \mathrm{min}$ & $69.62 \pm 14.84$ & $95.20 \pm 38.72$ & $0.030^{*}$ \\
\hline S. Cystatin C mg/L & $0.73 \pm 0.34$ & $0.95 \pm 0.32$ & $0.098+$ \\
\hline
\end{tabular}

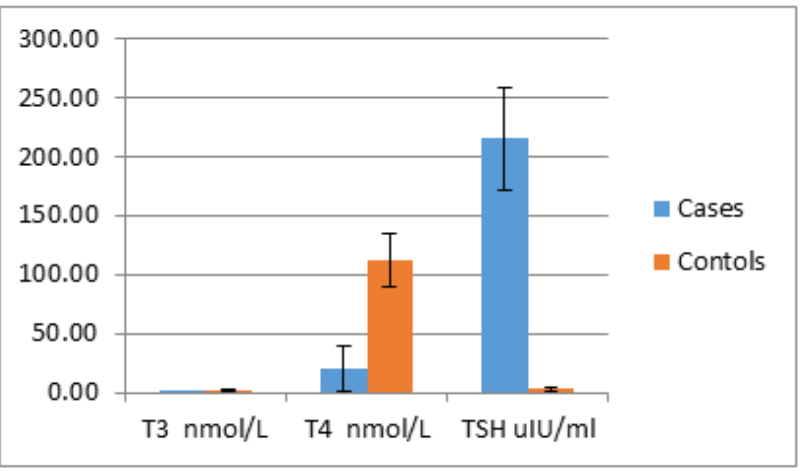

Fig-2: Thyroid profile in hypothyroid cases and euthyroid controls

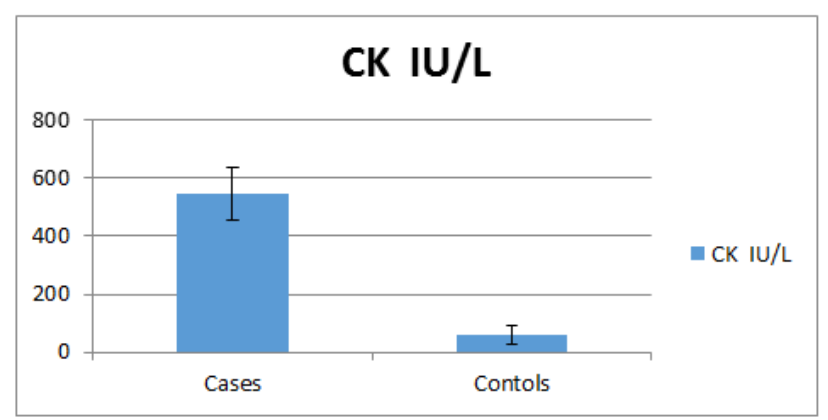

Fig-3: Serum Total CK (IU/L) in hypothyroid cases and euthyroid controls

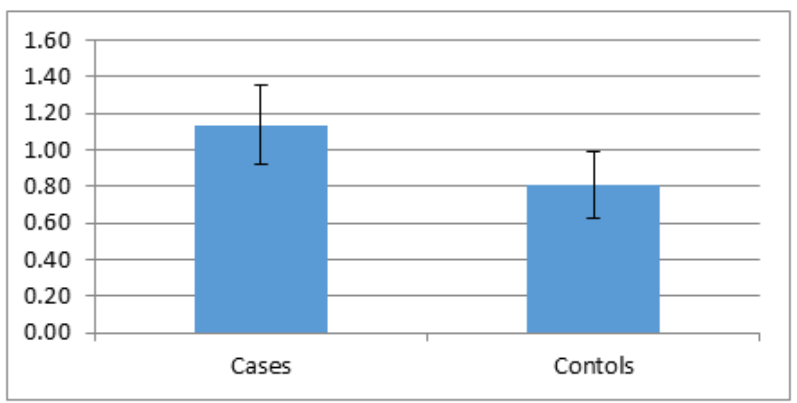

Fig-4: Serum Creatinine (mg/dl) in hypothyroid cases and euthyroid controls

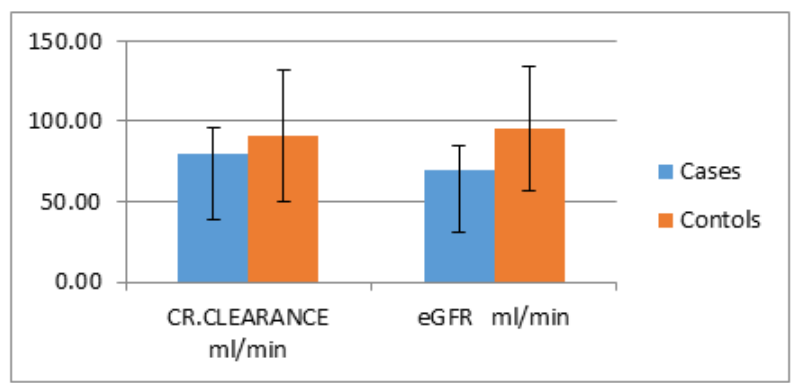

Fig-5: GFR ( $\mathrm{ml} / \mathrm{min})$ and creatinine clearance $(\mathrm{ml} / \mathrm{min})$ in hypothyroid cases and euthyroid controls 


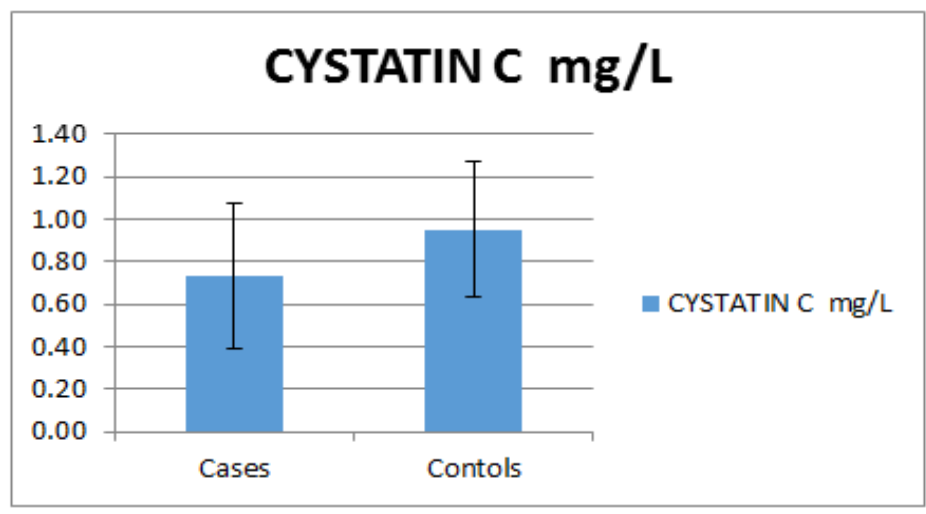

Fig-6: Serum Cystatin C (mg/L) in hypothyroid cases and euthyroid controls

The correlation of $\mathrm{T} 3$ with other thyroid hormones along with total CK, cystatin $\mathrm{C}$ and creatinine was studied. T3 being the active hormone and has shorter half-life does not directly correlated with the measured parameters, may exert its action via T3 receptors as in Table 3 .

Table-3: Pearson correlation of $T_{3}$ with $T_{4}$, TSH, Total CK, $S$. Creatinine, Creatinine clearance and eGFR in hypothyroids

\begin{tabular}{|l|l|l|}
\hline \multirow{2}{*}{ Pair } & \multicolumn{2}{|l|}{ Hypothyroid Cases } \\
\cline { 2 - 3 } & r value & p value \\
\hline $\mathrm{T}_{3} \mathrm{nmol} / \mathrm{L}$ vs $\mathrm{T}_{4} \mathrm{nmol} / \mathrm{L}$ & $\mathbf{0 . 5 2}$ & $\mathbf{0 . 0 5}+$ \\
\hline $\mathrm{T}_{3} \mathrm{nmol} / \mathrm{L}$ vs TSH $\mu \mathrm{IU} / \mathrm{ml}$ & 0.08 & 0.78 \\
\hline $\mathrm{T}_{3} \mathrm{nmol} / \mathrm{L}$ vs Total CK IU/L & -0.26 & 0.36 \\
\hline $\mathrm{T}_{3} \mathrm{nmol} / \mathrm{L}$ vs S.creatinine $(\mathrm{mg} / \mathrm{dl})$ & -0.44 & 0.11 \\
\hline $\mathrm{T}_{3} \mathrm{nmol} / \mathrm{L}$ vs Creatinine clearance $(\mathrm{ml} / \mathrm{min})$ & -0.06 & 0.83 \\
\hline $\mathrm{T}_{3} \mathrm{nmol} / \mathrm{L}$ vs eGFR(ml/min) & -0.12 & 0.68 \\
\hline $\mathrm{T}_{3} \mathrm{nmol} / \mathrm{L}$ vs S. Cystatin C $(\mathrm{mg} / \mathrm{dl})$ & -0.40 & 0.15 \\
\hline
\end{tabular}

There is significant correlation of TSH with total CK in the study indicating TSH levels can influence myopathy and release of muscle enzymes in hypothyroidism as in Table 4.

Table-4: Pearson correlation of TSH with Total creatine kinase, S. creatinine, Creatinine clearance and eGFR in hypothyroids

\begin{tabular}{|l|l|l|}
\hline \multirow{2}{*}{ Pair } & \multicolumn{2}{l|}{ Hypothyroid Cases } \\
\cline { 2 - 3 } & r value & p value \\
\hline TSH $\mu \mathrm{IU} / \mathrm{ml}$ vs Total CK level IU/L & 0.66 & $0.01+$ \\
\hline TSH $\mu \mathrm{IU} / \mathrm{ml}$ vs S. creatinine $(\mathrm{mg} / \mathrm{dl})$ & -0.11 & $: 0.70$ \\
\hline TSH $\mu \mathrm{IU} / \mathrm{ml}$ vs Creatinine clearance $(\mathrm{ml} / \mathrm{min})$ & 0.14 & 0.63 \\
\hline TSH $\mu \mathrm{IU} / \mathrm{ml}$ vs eGFR $(\mathrm{ml} / \mathrm{min})$ & -0.19 & 0.51 \\
\hline TSH $\mu \mathrm{IU} / \mathrm{ml}$ vs S. Cystatin C & -0.37 & 0.19 \\
\hline
\end{tabular}

There is negative correlation of total CK with creatinine, eGFR and creatinine clearance as in Table 5.

Table-5: Pearson correlation of Total CK level with S.creatinine, Creatinine clearance and eGFR in hypothyroids

\begin{tabular}{|l|l|l|}
\hline \multirow{2}{*}{ Pair } & \multicolumn{2}{|l|}{ Hypothyroid Cases } \\
\cline { 2 - 3 } & r value & p value \\
\hline Total CK level (IU/L) vs S. creatinine (mg/dl) & -0.50 & 0.06 \\
\hline Total CK level (IU/L) vs Creatinine clearance (ml/min) & 0.22 & 0.44 \\
\hline Total CK level (IU/L) vs eGFR (ml/min) & -0.30 & 0.29 \\
\hline Total CK level (IU/L) vs S. Cystatin C (mg/L) & -0.55 & 0.04 \\
\hline
\end{tabular}

There is significant correlation of eGFR with creatinine clearance as in table 6 . 
Table-6: Pearson correlation of eGFR with other profiles in Hypothyroids

\begin{tabular}{|l|l|l|}
\hline \multirow{2}{*}{ Pair } & \multicolumn{2}{l|}{ Hypothyroid Cases } \\
\cline { 2 - 3 } & r value & p value \\
\hline eGFR $(\mathrm{ml} / \mathrm{min})$ vs T $_{3}(\mathrm{nmol} / \mathrm{L})$ & -0.12 & 0.68 \\
\hline eGFR(ml/min) vs $\mathrm{T}_{4}(\mathrm{nmol} / \mathrm{L})$ & -0.27 & 0.35 \\
\hline eGFR $(\mathrm{ml} / \mathrm{min})$ vs TSH $(\mu \mathrm{IU} / \mathrm{ml})$ & -0.19 & 0.51 \\
\hline eGFR $(\mathrm{ml} / \mathrm{min})$ vs Total CK level $(\mathrm{IU} / \mathrm{L})$ & -0.30 & 0.29 \\
\hline eGFR $(\mathrm{ml} / \mathrm{min})$ vs S. creatinine $(\mathrm{mg} / \mathrm{dl})$ & -0.68 & $<0.01^{* *}$ \\
\hline eGFR $(\mathrm{ml} / \mathrm{min})$ vs Creatinine clearance $(\mathrm{ml} / \mathrm{min})$ & -0.76 & $<0.01^{* *}$ \\
\hline eGFR $(\mathrm{ml} / \mathrm{min})$ vs S. Cystatin C $(\mathrm{mg} / \mathrm{L})$ & -0.01 & 0.97 \\
\hline
\end{tabular}

Hypothyroidism is a common endocrine disorder associated with decreased myocardial contractility, cardiac output and increase in peripheral vascular resistance. The increase in peripheral resistance can predispose to the alteration in renal hemodynamics such as reduced renal blood flow and diminution of glomerular filtration rate resulting in decrease in the clearance of certain substances like creatine kinase, creatinine and others in hypothyroidism [9]. Hypothyroidism may be contributing to the low GFR in some of the hypothyroid cases [10]. Renal function deterioration secondary to hypothyroidism involves heterogenous mechanisms which includes negative inotropic effect on the heart, reduced circulating intravascular volume and increased peripheral resistance with renal vasoconstriction [4]. The elevation in total CK level in hypothyroids in the study could be due to release of CK from the skeletal muscles (Table 2). The pituitary gland releases TSH in response to suboptimal level of thyroid hormones, similarly the muscles may also respond by releasing creatine kinase into the circulation in hypothyroidism. Several authors have also reported elevation of serum CK activities correlating with the severity of hypothyroidism. Hypothyroids have increased level of $\mathrm{CK}$, due to increased CK-MM isoenzyme which indicates skeletal muscle as the major source of the increased plasma CK level. Skeletal muscles are more receptive to alteration in $\mathrm{TSH}$ level as compared to renal system.

The study shows elevation in serum total CK level in hypothyroids as compared to controls (Fig 3). The CK level is increased ten folds in hypothyroids as compared to controls. The increase in total CK level may be due to increase in concentration of the enzyme in circulation as a result of leakage of the enzyme from muscle cells. There may be decrease in renal blood flow thereby affecting the clearance of $\mathrm{CK}$ from the circulation. Serum muscle enzyme elevations in hypothyroidism, which occur in the absence of weakness, myalgia's or structural muscle abnormalities, could to be due to changes in muscle cell membrane permeability, although the basis for this change is unknown [11]. There may be decrease in renal blood flow thereby affecting the clearance of CK from the circulation. Reduced clearance of creatine kinase (CK) probably also plays a role in hypothyroidism [12].
A positive correlation was observed between TSH and CK level in hypothyroids in the study indicates the influence of TSH on myopathy, though the rise in CK level was nearly ten times more (Table 4). The presence of $\mathrm{T}_{3}$ receptors on the mitochondrial membrane of skeletal muscles suggests a direct effect of thyroid hormones on oxidative metabolism in muscles and may be one of the causes for muscle dysfunction in hypothyroidism [13]. The hypometabolic state of hypothyroidism can cause reduction in glycolysis and oxidative phosphorylation thereby reducing ATP concentrations beyond a critical limit. Mitochondrial defect and reduction in oxidative phosphorylation may contribute to impaired oxygen use in hypothyroidism resulting in increased lactate concentration [14]. It has been reported alteration in sarcolemmal membranes can cause increased cell permeability and leakage of CK from cells. High serum CK concentration in hypothyroidism may be due to muscle fiber degeneration, altered muscle energy metabolism and decreased clearance of $\mathrm{CK}$ from circulation [15].

The effects of hypothyroidism on renal system include changes in water and electrolyte metabolism, notably hyponatremia and alterations of renal hemodynamics including decrements in renal blood flow, GFR and single nephron GFR [16]. The decreases in renal plasma flow and glomerular filtration rate (GFR) that accompany hypothyroidism are believed to be related to the generalized hypodynamic state of the circulatory system in hypothyroidism. Elevation of serum creatinine levels is not generally mentioned as an abnormality that occurs in association with hypothyroidism. Thyroid dysfunction may alter creatinine, which has been found to be increased in hypothyroidism and decreased in hyperthyroidism. The study was taken up to evaluate whether changes in Cys $\mathrm{C}$ and creatinine are similar during diagnosis of hypothyroidism. Serum cystatin $\mathrm{C}$ being is a low molecular weight, basic protein that functions as a physiologic inhibitor of cysteine proteinases and is produced at a constant rate by most nucleated cells [17]. Cystatin $\mathrm{C}$ gene is of the housekeeping type and the production of Cys $\mathrm{C}$ is not influenced by inflammatory states. The protein is freely filtered at the glomerulus and practically completely reabsorbed and catabolized by tubular cells [18]. In comparison to serum creatinine, Cys $\mathrm{C}$ has a lower inter individual 
variability and is not correlated to lean tissue mass, gender, and age. Cys $\mathrm{C}$ has proved to be a reliable marker of glomerular filtration rate (GFR) in healthy adults and children. Highly significant correlation between cystatin $\mathrm{C}$ and TSH was not observed in the study (Table 4) This further indicates Cystatin C, a novel marker for renal dysfunction, when estimated and used for calculating glomerular filtration rate, the results have to be used with caution as decreased thyroid hormone levels and other clinical condition can influence their serum levels. The hypothyroid cases in the study did not have very evident renal failure. The cases recruited for the study were not treated for renal dysfunction.

The study shows a significant increase in serum creatinine in hypothyroids ( $p$ value $<0.001$ ) when compared with controls (Table 2). Tayal et al. have also reported significant elevation in serum creatinine levels in hypothyroids [19]. There is correlation between TSH and $\mathrm{CK}$ level in hypothyroid cases but correlation between TSH and creatinine was not very significant, may be due to involvement of skeletal muscle before renal dysfunction (Table 4).

The renal involvement in hypothyroidism is evident by significant correlation of eGFR with serum creatinine and creatinine clearance in hypothyroids (Table 5). Kreisman et al. have reported the rise in serum creatinine level can be due to a decrease in the GFR and is a reversible condition [20]. The cause for decrease in GFR can be due to hypodynamic circulation in hypothyroidism. The cause for elevation of serum creatinine can be either due to decrease in GFR or due to decrease in renin levels consequently reducing the level of renin angiotensin system [21]. There is decreased sensitivity to $\beta$-adrenergic stimulus and decreased renin release, along with decreased angiotensin II levels and impaired RAAS activity resulting in decreased filtration rate [22].

The rise in serum creatinine levels in hypothyroids can be partly due to the influence of $\mathrm{T}_{3}$, $\mathrm{T}_{4}$ and TSH on renal function and also due to rise in CK level. Increased serum creatinine level, decreased eGFR and decline in creatinine clearance are observed in hypothyroidism. The reduction of cystatin $\mathrm{C}$ levels in hypothyroids may be due to involvement of muscle cell associated with increase in creatine kinase level. The rise in CK level and serum creatinine could be either due to reduced clearance or due to overproduction or both.

\section{CONCLUSION}

The elevation of serum creatinine levels in hypothyroidism may be associated with increase in total creatine kinase level either due to myopathy or due to decreased clearance by kidney. There is paradoxical relation of elevation of serum creatinine and decrease in serum cystatin $\mathrm{C}$ in hypothyroidism warrants the use of cystatin C for estimating GFR in hypothyroidism with caution. However, further studies are required in large population to verify the utility of serum cystatin C estimation in hypothyroids in whom otherwise serum creatinine may be a better indicator of renal involvement.

\section{REFERENCES}

1. Mariani, L.H., Berns, J.S. (2012). The Renal Manifestations of Thyroid Disease. JASN, 23(1): 22-26.

2. Larsen, P.R., Zavacki, A.M. (2012). Role of the Iodothyronine Deiodinases in the Physiology and Pathophysiology of Thyroid Hormone Action. Eur Thyroid J, 1: 232-242.

3. Kim, E.O., Lee, I.S., Choi, Y.A., Lee, S.J., Chang, Y.K., Yoon, H.E., Hwang, H.S. (2013). Unresolved subclinical hypothyroidism is independently associated with progression of chronic kidney disease. International journal of medical sciences, 11(1), 52-59.

4. Petkov, S.V., Juan, A., Navarroa, M., Herreroa, E.M., Sáncheza, M.J.G.(2010). Decrease in renal function associated with hypothyroidism. Nefrología, 30(3): 271-380.

5. Katz, A.I. (1982). Renal Na-K-ATPase: its role in tubular sodium and potassium transport. Am J Physio, 242(3): F207-219.

6. Rhee, C.M. (2016). The interaction between thyroid and kidney disease: an overview of the evidence. Current opinion in endocrinology, diabetes, and obesity, 23(5): 407-415.

7. Fricker, M., Wiesli, P., Brändle, M., Schwegler, B., Schmid, C. (2003). Impact of thyroid dysfunction on serum cystatin C. Kidney Int, 63(5):1944-1947.

8. Levey, A.S., Coresh, J., Greene, T., Marsh, J., Stevens, L.A., Kusek, J.W.(2007). Chronic Kidney Disease Epidemiology Collaboration. Expressing the Modification of Diet in Renal Disease Study equation for estimating glomerular filtration rate with standardized serum creatinine values. Clin Chem, 53(4): 766-772.

9. Patil, V.P., Alagilwada, S.S., Vidya, S.P. (2018). Evaluation of renal function in subclinical hypothyroidism. Journal of laboratory physicians, 10(1):50-55.

10. Chang, Yi-Cheng. (2018). Subclinical and overt hypothyroidism is associated with reduced glomerular filtration rate and proteinuria: a large cross-sectional population study. Scientific reports, 8, 2031.

11. McGrowder, D.A., Fraser, Y.P., Gordon, L., Crawford, T.V., Rawlins, J.M. (2011). Serum creatine kinase and lactate dehydrogenase activities in patients with thyroid disorders. Niger J Clin Pract, 14: 454-459.

12. Hekimsoy, Z., Oktem, I.K. (2005). Serum creatine kinase levels in overt and subclinical hypothyroidism. Endocr Res, 31(3): 171-175. 
13. Salvatore, Domenico. (2014). Thyroid hormones and skeletal muscle--new insights and potential implications. Nature reviews. Endocrinology, 10(4): 206-214.

14. Stepien, Karolina, M. (2017). Evidence of Oxidative Stress and Secondary Mitochondrial Dysfunction in Metabolic and Non-Metabolic Disorders. Journal of clinical medicine, 6(71): 125.

15. Giampietro, O., Clerico, A., Buzzigoli, G., Del Chicca, M.G., Boni, C., Carpi, A. (1984). Detection of hypothyroid myopathy by measurement of various serum muscle markers-myoglobin, creatine kinase, lactate dehydrogenase and their isoenzymes. Correlations with thyroid hormone levels (free and total) and clinical usefulness. Horm Res, 19(4): 232-242.

16. Mahata1, M.K., Chowdhury, S.P., Dey, S. (2019). Renal Function Impairment in Hypothyroid Patient: A Study from Eastern India. IJMACR, 2: 59-64.

17. Randers, E.1., Kristensen, J.H., Erlandsen, E.J, Danielsen, H. (1998). Serum cystatin C as a marker of the renal function. Scand J Clin Lab Invest, 58(7): 585-592.
18. Mussap, M., Vestra, M.D., Fioretto, P., Saller, A., Varagnolo, M.C., Nosadini, R., Plebani, M. (2002). Cystatin $C$ is a more sensitive marker than creatinine for the estimation of GFR in type 2 diabetic patients. Kidney International, 61: 14531461.

19. Tayal, D., Chawla, R., Arora, S., Gupta, V.K., Sohi, S.J., Mallika, V. (2009). Dynamic changes in biochemical markers of renal function with thyroid status - a study in Indian population. Internet Journal of Medical Update, 4(2): 36-41.

20. Kreisman, S.H., Hennessey, J.V. (1999). Consistent reversible elevations of serum creatinine levels in severe hypothyroidism. Arch Intern Med, 159(1): 79-82.

21. Remuzzi, G.1., Perico, N., Macia, M., Ruggenenti, P. (2005). The role of renin-angiotensinaldosterone system in the progression of chronic kidney disease. Kidney Int Suppl, 99: S57-65.

22. Basu, G., Mohapatra, A. (2012). Interactions between thyroid disorders and kidney disease. Indian journal of endocrinology and metabolism, 16(2): 204-13. 